УДК 661.879.1:622.258.4:551.49:539.16

\title{
ПРОСТРАНСТВЕННОЕ РАСПРЕДЕЛЕНИЕ ХИМИЧЕСКИХ ЭЛЕМЕНТОВ В ВОДОТОКЕ ШТОЛЬНИ 504 ПЛОЩАДКИ «ДЕГЕЛЕН»
}

\author{
Шакенов Ербол Зейнелгазинович1, \\ shakenov@nnc.kz
}

\author{
Дюсембаева Мадина Талгатовна 1 , \\ koigeldinova@nnc.kz
}
Лукашенко Сергей Николаевич², lukashenko.1962@mail.ru

Темиржанова Арай Ермековна ${ }^{1}$, temirzhanova@nnc.kz

\section{Есильканов Гани Мухтарович1, al-g_007@mail.ru}

\author{
Мухамедияров Нурлан Жумагазыевич1, \\ mukhamediyarov@nnc.kz \\ 1 Институт радиационной безопасности и экологии, \\ Казахстан, 071100, г. Курчатов, ул. Бейбит атом, 2. \\ 2 Всероссийский научно-исследовательский институт радиологии и агроэкологии, \\ Россия, 249032, г. Обнинск, Киевское шоссе, 109 км.
}

Актуальность работы обусловлена необходимостью получения современных данных о концентрации химических элементов в системе «вода-почва-растения» на припортальном участке штольни 504 площадки «Дегелен» бывшего Семипалатинского испытательного полигона. В период весеннего половодья возможен вынос элементов за пределы площадки штольни 504. Цель: изучение пространственного распределения химических элементов в системе «вода-почва-растения» в водотоке штольни 504. Для достижения данной цели были поставлены следующие задачи: 1) определить уровни концентрации химических элементов в воде; 2) изучить уровни концентрации химических элементов в почве; 3) вьявить особенности накопления химических элементов в растениях штольни 504.

Методы. Элементный состав воды определялся методами масс-спектрометрии с индуктивно-связанной плазмой (Elan 9000 "Perkin Elmer SCIEX»), атомно-эмиссионной спектрометрии с индуктивно-связанной плазмой («іСAP 6300 Duо» Thermo Scientific). Анализ таких показателей, как общая минерализация, содержание сульфатов, гидрокарбонатов, хлоридов, кальция, магния и натрия, проводился титриметрическими, колориметрическими, потенциометрическими методами в соответствии с ГОСТ.

Результаты. Анализ данных, полученных по воде, показал высокое содержание таких элементов, как Li, Be, Al, Mn, Zn, Rb, Sr, $\mathrm{Cd}, \mathrm{Cs}, \mathrm{La}, \mathrm{Ce}, \mathrm{U}$, среднее содержание которых в несколько раз превышает показатель кларка в подземных водах аридного климата (сульфратные воды). Также для воды замечено превышение предельно допустимых уровней для таких элементов, как Be (2800 ПДК), Mn (260 ПДК), Al (76 ПДК), U (70 ПДК) и Cd (50 ПДК). По последним данным выявлено, что содержание таких элементов, как Li, Be, Al, в воде увеличилось в 2 раза, тогда как Co, Ni u Cu - в десятки раз.

Пространственное распределение исследуемых элементов в почве штольни 504 неоднородно, большая часть элементов кониентрируется в грунте севернее русла водотока. На данном участке выявлено повышенное содержание таких элементов, как $\mathrm{Be}, \mathrm{Mn}, \mathrm{Cu}, \mathrm{Zn}, \mathrm{Mo}, \mathrm{Cd}, \mathrm{Cs}, \mathrm{Pb}$ u U, превышающих показатель кларка литосфреры. Индекс превышения значения кларка литосферы составил для концентрации урана 1000 раз. Сравнение полученных данных на загрязненных участках со значением предельно-допустимых концентраций химических элементов для почвы выявило превышение у Рb (26 ПДК), Mn и Си (9 ПДК). Химический состав воды и почвы штольни 504 является уникальным по содержанию редкоземельных элементов. Среднее содержание РЗЭ в воде в тысячу раз превышает показатель кларка в подземных водах аридного климата и подземных водах СИП. Замечено превышение предельно допустимого уровня концентрации для самария в воде. Характерным является преобладание группы легких РЗЭ с ярко выраженной церий-лантановой специализацией.

Для большинства видов растений штольни 504 на загрязненном участке выявлено повышенное содержание $\mathrm{Be}, \mathrm{Cd}, \mathrm{Cs}, \mathrm{Pb}, \mathrm{U}$ и ряда РЗЭ. Концентрация исследуемых элементов в таких видах растений, как тростник и вейник, на сравниваемых участках менялась незначительно, что, видимо, обусловлено наличием физиолого-биохимических механизмов, препятствующих их поступлению.

Исходя из вышеизложенного, можно сделать вывод, что пространственное распределение элементов на площадке штольни 504 связано, прежде всего, с выносом химических элементов штольневыми водами. В воде штольни 504 выявлено порядка десяти элементов, превышающих значения кларка и предельно допустимые уровни.

Ключевые слова:

Семипалатинский испытательный полигон, площадка «Дегелен», штольня, химические элементы, предельно допустимые концентрации, кларк, редкоземельные элементы. 


\section{Введение}

Испытательная площадка «Дегелен» Семипалатинского испытательного полигона (СИП) использовалась для проведения подземных ядерных испытаний средней и малой мощности. В период с 1961 по 1989 гг. было проведено 209 ядерных испытаний в 181 штольне, которые расположены в горном массиве Дегелен. Штольни представляют собой горизонтальную выработку в гранитном массиве горы, их длина варьирует от нескольких сотен метров до 2 км. При этом диаметром ствола выработки штолен составляет около 3 м [1,2].

На площадке «Дегелен» по данным ранних исследований [3] были выявлены участки с повышенным содержанием радионуклидов в почве, воде и растительности. Возможно, данные участки образовались вследствие систематического выноса водным путем радионуклидов из штолен или вскрытия штолен по завершению испытаний, либо возникновения аварийных ситуации при проведении ядерных взрывов.

По ранее изученным данным на площадке «Дегелен» наиболее загрязненные участки - припортальные площадки следующих штолен с водотоками - 104 176, 504, 511, 177. За период работы испытательной площадки водоприток отмечался более чем в 50 штольнях. В донных отложениях штольневых водотоков существуют участки с концентрацией ${ }^{239+240} \mathrm{Pu}$ до $\mathrm{n} \cdot 10^{4}$ Бк/кг, ${ }^{90} \mathrm{Sr}-$ от $\mathrm{n} \cdot 10^{4}$ до $\mathrm{n} \cdot 10^{5}$ Бк/кг, ${ }^{137} \mathrm{Cs}$ - от n $10^{4}$ до $\mathrm{n} \cdot 10^{6}$ Бк/кг [1-4].

В водотоке штольни 504, расположенном в долине ручья Карабулак, помимо техногенных радионуклидов выявлено аномально высокое содержание редкоземельных элементов и тяжелых металлов $[5,6]$. Основной целью данной работы являлось изучение пространственного распределения химических элементов в системе «вода-почва-растения» в водотоке штольни 504. Для достижения данной цели были поставлены следующие задачи: 1) определить уровни концентрации химических элементов в воде; 2) изучить уровни концентрации химических элементов в почве; 3) выявить особенности накопления химических элементов в растениях штольни 504.

\section{Методы и объекты исследования}

\section{Краткое описание объекта исследования}

Горы Дегелен относятся к региональной гидрогеологической системе, примыкающей к левобережной части бассейна реки Иртыш. Основным источником питания водоисточников на территории горного массива Дегелен являются атмосферные осадки. Большинство штолен массива Дегелен расположено в зоне «транзита» атмосферных вод на различном удалении от уровня подземного бассейна трещинных вод. Поэтому при сооружении штолен практически всегда наблюдалось появление воды $[2,3]$.

Объектом исследования являлся водоток штольни 504, который расположен в долине ручья Карабулак (рис. 1). Всего в штольне 504 было произведено два подземных взрыва мощностью менее 0,001 и до 20 кт.

Среднегодовой дебит воды в штольне 504 составляет около 100 л/мин [4, 7]. Туннель штольни законсервирован, засыпан щебнем и гранитными камнями. В 50 м от штольни наблюдаются локальные участки с водопроявлениями, а постоянный водоток проявляется в 100 м от штольни. Длина ручья около 400 м. Ручей высыхает по мере удаления от портала штольни.

Припортальный участок штольни отличается наличием густого растительного покрова, где произрастают такие доминирующие виды растений как: тростник южный (Phragmites australis), вейник наземный (Calamagrostis epigeos), тысячелистник азиатский (Achilea asiatica), таволга зверобоелистная (Spirea hipericifolia), осока приземистая (Carex supina), полынь эстраган (Artemisia dracunculus), ковыль волосатик (Stipa capillata), типчак валлииский (Festuca valesiaca), ива остролистная (Sálix acutifólia), карагана древовидная (Caragana arborescens).
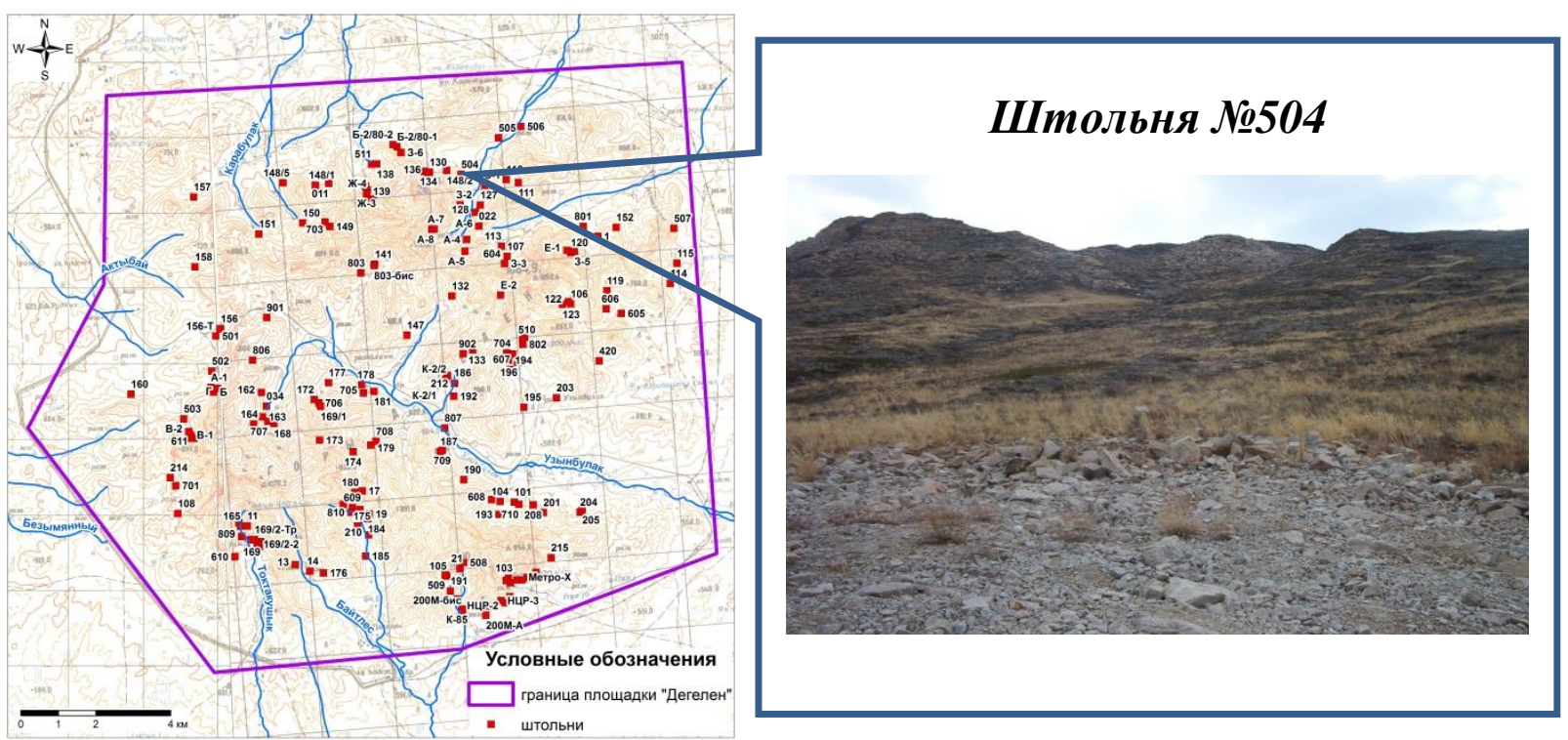

Рис. 1. Расположение штольни № 504 на площуадки «Дегелен»

Fig. 1. Location of tunnel 504 at «Degelen» site 


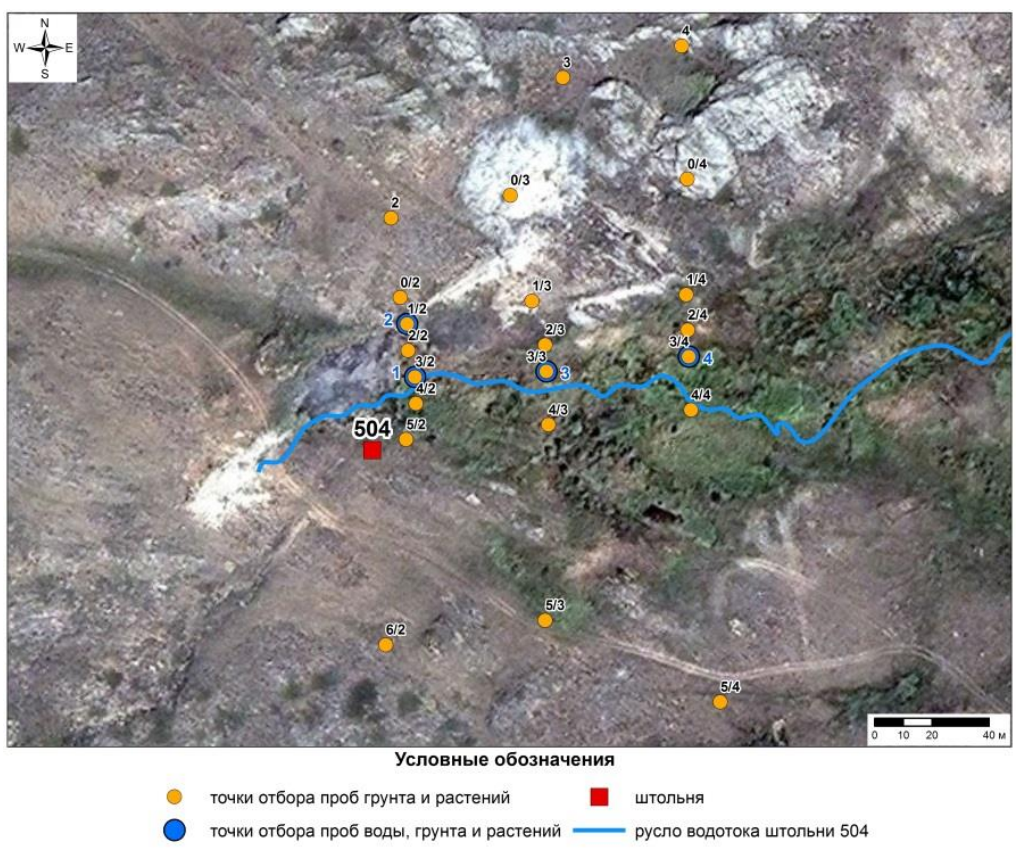

Puc. 2. Точки отбора проб воды, грунта и растений

Fig. 2. Water, soil and plant sampling points

\section{Отбор проб и методы исследования}

Вдоль русла водотока штольни 504 (на расстоянии 50-150 м от портала штольни) в сентябре 2012 г. производился отбор проб воды, почвы и растений. Для определения местоположения точек в географической системе координат использовался GPS-приемник Garmin Rino 520, который позволяет определять положение точек с точностью $\pm 5 \mathrm{M}$.

Отбор проб на исследуемом участке проводился по трем профилям, расстояние между которыми составляет 50 м. Каждый профиль был предварительно разделен на 6-8 участков, где производился отбор проб. Расстояние между участками отбора проб от русла водотока штольни по каждым профилям составляет 10, 20, 40 и 100 м соответственно. Условно серединой исследуемых профилей взято русло водотока, где проводился отбор проб воды. Точки отбора проб на припортальном участке штольни 504 приведены на рис. 2.

\section{Отбор проб воды}

Пробоотбор воды выполнен согласно ГОСТ Р 51592-2000 [8, 9], который распространяется на любые типы вод и предназначен для определения показателей ее химического состава и свойств.

Для удаления крупных включений и механических примесей пробы воды фильтровались бумажным фильтром «синяя лента». Далее отфильтрованные пробы консервировались путем добавления концентрированной азотной кислоты марки «осч» (3 мл $\mathrm{HNO}_{3}$ на 1 л пробы).

Для проведения общехимического анализа отдельно отобрано 1,5 л воды, которая не подлежит консервированию согласно ГОСТ [8, 9]. Был проведен ряд анализов по определению общей минерализации, содержания сульфатов, гидрокарбонатов, хлори- дов, кальция, магния и натрия согласно утвержденным стандартным методикам [10].

\section{Отбор и подготовка проб почвь}

Процесс отбора проб проводился методом укола из поверхностного слоя 0-5 см донного осадка на площади $100 \mathrm{~cm}^{2}$ согласно ГОСТ 17.1.5.01-80 «Охрана природы. Гидросфера. Общие требования к отбору проб донных отложений водных объектов для анализа на загрязненность».

Отобранные пробы почвы весом не менее 1 кг просушивались на воздухе до воздушно-сухого веса. Влажные пробы почвы сушились в сушильном шкафу при температуре $105^{\circ} \mathrm{C}$ в течение 3-6 часов. Воздушно-сухие пробы почвы просеивались через полиамидное сито с диаметром отверстий 1 мм. Методом квартования отбирался образец массой 200 г и истирался на дисковой мельнице «Pulverisette 9» (гарнитура закаленная сталь) в течение 20 минут со скоростью вращения 1000 об/мин. Повторно отбирали из перемолотого гомогенного образца методом квартования навеску 50 г и дополнительно истирали в течение 20 минут. Далее отбирали из перемолотого гомогенного образца конечную навеску для анализа массой 0,2 г.

\section{Отбор и подготовка проб растений}

Сопряженно с пробами почвы осуществлялся отбор надземной части растений. Для анализа были взяты пробы шести видов растений, относящиеся к разным экологическим группам (гидрофиты, мезофиты, ксерофиты). Из них гидрофиты: вейник наземный, тростник южный и осока приземистая; мезофиты: карагана древовидная; ксерофиты: ковыль волосатик и полынь эстраган.

Отбираемую часть срезали на высоте 3-5 см с помощью ножниц из нержавеющей стали и упаковыва- 
ли в полиэтиленовый пакет. Производился отбор надземной части растений в первичной сырой массе порядка 500 г. В лаборатории пробы промывались дистиллированной водой с целью удаления частичек почвы и высушивались при комнатной температуре. Обобщенно подготовку можно представить в виде взвешивания, последовательного измельчения воздушно-сухой пробы растения на отрезки 5-8 мм, отбора среднего образца методом квартования (массой 100 г), измельчения на электромельнице «Grindomix GM 200», отбора методом квартования конечной навески для анализа массой 5 г.

\section{Подготовка образцов к анализу}

Вода. Отбиралась аликвота пробы воды объемом 1 мл, разбавлялась в соотношении 1:10 и анализировалась на содержание интересующих элементов.

Почва. Разложение проб почвы и растений проводилось согласно методическим указаниям [11] и рабочей инструкции РИ 03-02-03 (А) «Подготовка проб для элементного анализа методом автоклавного разложения» $[12,13]$.

Навеску образца почвы массой $200,0 \pm 0,1$ мг помещали в тефлоновый вкладыш и добавляли небольшими порциями $10 \mathrm{~cm}^{3} 7 \mathrm{M}$ азотной кислоты. Затем тефлоновый вкладыш вставляли в автоклав, который зажимали в станине. Автоклавное разложение проб проводили в течение 2,5 ч при температуре $160{ }^{\circ} \mathrm{C}$. По окончании автоклавирования охлажденную пробу переносили в центрифужную пробирку и центрифугировали в течение 10 мин при частоте вращения 10000 об/мин, затем центрифугат переносили в мерную пробирку объёмом $15 \mathrm{~cm}^{3}$, осадок промывали 5 $\mathrm{cm}^{3} 7 \mathrm{M}$ азотной кислоты и снова центрифугировали. Центрифугат и промывной раствор объединяли и доводили 7М азотной кислотой до объема $15 \mathrm{~cm}^{3}$. Полученный таким образом исходный раствор разбавляли $1 \%$ раствором $\mathrm{HNO}_{3}$ в соотношении 1:100 и анализировали на содержание химических элементов [13].

Растения. Навеску сухой пробы растения $0,5000 \pm 0,0001$ г помешали во фторопластовый вкладыш автоклава, смачивали 1 мл $\mathrm{H}_{2} \mathrm{O}$, добавляли 6 мл конц. $\mathrm{HNO}_{3}$ и 1 мл $30 \% \mathrm{H}_{2} \mathrm{O}_{2}$. Через 40 минут фторопластовый вкладыш закрывали крышкой, вставляли во внешний корпус автоклава и помещали в стальную станину с зажимным устройством. Станину с автоклавом помещали в сушильный шкаф, разогретый до $160 \pm 5^{\circ} \mathrm{C}$, и выдерживали в течение 2,5 ч. По окончании автоклавирования охлажденную пробу количественно переносили в мерную пробирку и доводили $1 \%$ раствором азотной кислоты до объема $15 \mathrm{~cm}^{3}$. Полученный таким образом раствор разбавлялся $1 \%$ раствором $\mathrm{HNO}_{3}$ в соотношении 1:10 и анализировался на содержание интересующих элементов.

\section{Проведение аналитических работ}

Определение содержания химических элементов проводилось методами масс-спектрометрии (ИСП-МС) и атомно-эмиссионной спектрометрии (ИСП-АЭС) с индуктивно-связанной плазмой. Были использованы приборы Elan 9000 производства США компании
«Perkin Elmer SCIEX» и «iCAP 6300 Duo» производства Великобритании фирмы «Thermo Scientific». Для построения градуировочной кривой применялись многоэлементные стандартные растворы, имеющие код в реестре государственных средств измерений Республики Казахстан под № KZ.03.02.00901-2010, KZ.03.02.00902-2010. Внутренний контроль качества во время испытаний проводился с помощью анализа стандартного раствора через каждые 10 проб. В случае результатов, несоответствующих требованиям внутреннего контроля качества, проводилось дополнительное построение градуировочной кривой и сам процесс анализа проб с учетом новых параметров фона. Измерение исследуемых проб проводилось по методике ISO 17294-2:2003 (E) [14].

Вариационно-статистический и корреляционный, а также регрессионный анализы $[15,16]$ полученных данных проводились с помощью программ STATISTICA и Microsoft Excel.

Для характеристики химического состав воды использована формула Курлова.

\section{Результаты исследования}

Исследование элементного состава водотока штольни 504

Ионный состав рассматриваемого водного объекта весьма разнообразен. Химический состав воды штольни 504 демонстрирует составленная на его основе формула Курлова:

$$
\text { M } 1,5 \frac{\mathrm{SO}_{4}^{2-} 22}{\mathrm{Ca} 9,6 \mathrm{Mg} 8,6} \mathrm{pH} \mathrm{5,2.}
$$

Как видно из формулы, вода штольни 504 относится к сульфатно-кальциево-магниевому типу.

Анализ данных показал, что штольневые воды относятся к кислым водам $(\mathrm{pH}=5,0-5,5)$. По степени минерализации вода штольни 504 является солоноватой $(1,5$ г/л), по значению жесткости относится к группе жестких вод (>9,0 ммоль/л).

Элементный состав воды штольни 504 представлен в табл. 1.

Как видно из таблицы, среднее содержание большинства элементов в воде штольни 504, отобранных в профилях, характеризуется небольшими пределами колебаний. Однако высокий размах колебаний концентраций отмечен для следующих элементов: $\mathrm{Fe}, \mathrm{Co}$, $\mathrm{Ni}, \mathrm{Cu}, \mathrm{Ga}, \mathrm{As}, \mathrm{Ba}, \mathrm{Mo} \mathrm{и} \mathrm{Pb}$. По-видимому, это связано с наличием подтоков воды на различных участках русла водотока штольни 504, что объясняет неоднородность содержания вышеперечисленных элементов в пробах воды.

О стабильности содержания элементов в воде 504 штольни можно судить при сравнении их концентрации с ранее полученными данными. Из таблицы видно, что концентрация большинства элементов в воде меняется незначительно. Отмечено, что по последним данным содержание таких элементов, как $\mathrm{Li}, \mathrm{Be}, \mathrm{Al}$, в воде увеличилось в 2 раза, тогда как $\mathrm{Co}, \mathrm{Ni}$ и $\mathrm{Cu}-$ в десятки раз. Также следует отметить, что в воде штольни 504 выявлены такие элементы, как Fe, Mo и $\mathrm{Pb}$, концентрация которых в ранее полученных данных была меньше предела обнаружения. 
Известия Томского политехнического университета. Инжиниринг георесурсов. 2020. Т. 331. № 9. 70-83 Шакенов Е.З. и др. Пространственное распределение химических элементов в водотоке штольни 504 площадки «Дегелен»

Таблица 1. Среднее содержание и предель колебания химических элементов в воде штольни 504, мкг/л, $n=4$

Table 1. Average content and variation limits of chemical elements in water of tunnel $504, \mu \mathrm{g} / \mathrm{l}, n=4$

\begin{tabular}{|c|c|c|c|c|c|c|}
\hline \multirow[b]{2}{*}{$\begin{array}{l}\text { Элементы } \\
\text { Elements }\end{array}$} & \multirow[b]{2}{*}{$\begin{array}{c}\bar{x} \pm S \bar{x} \\
(2012 \text { г.) }\end{array}$} & \multirow[b]{2}{*}{$\begin{array}{l}\mathrm{C}_{\max } \\
\mathrm{C}_{\min }\end{array}$} & \multicolumn{3}{|c|}{ Среднее содержание/Average concentration } & \multirow[b]{2}{*}{$\begin{array}{c}\text { ПДК } \\
\text { МРС } \\
{[20]}\end{array}$} \\
\hline & & & $\begin{array}{c}\text { в воде штольни } 504 \\
2010 \text { г. } \\
\text { in water of tunnel 504, } \\
2010 \text { [17] }\end{array}$ & $\begin{array}{c}\text { в подземных водах аридного кли- } \\
\text { мата (сульфатные воды) } \\
\text { in ground water of the arid climate } \\
\text { (sulfate water) [18] }\end{array}$ & $\begin{array}{l}\text { в эталонной прес- } \\
\text { ной воде } \\
\text { in standard fresh } \\
\text { water [19] }\end{array}$ & \\
\hline $\mathrm{Li}$ & $330 \pm 30$ & 1,2 & $125 \pm 120$ & 29 & 3 & 30 \\
\hline $\mathrm{Be}$ & $560 \pm 60$ & 1,2 & $270 \pm 25$ & 0,09 & 0,1 & 0,2 \\
\hline $\mathrm{Na}$ & $3500 \pm 510$ & 1,4 & $27000 \pm 3000$ & 275000 & 5000 & 200000 \\
\hline $\mathrm{Mg}$ & $26800 \pm 3000$ & 1,3 & $23000 \pm 2000$ & 60300 & 4000 & 20000 \\
\hline $\mathrm{Al}$ & $38000 \pm 4500$ & 1,2 & $17600 \pm 1700$ & 280 & 200 & 500 \\
\hline $\mathrm{K}$ & $1700 \pm 460$ & 1,7 & $2500 \pm 200$ & 15800 & 2000 & - \\
\hline $\mathrm{Ca}$ & $28000 \pm 1300$ & 1,1 & $185000 \pm 18000$ & 118000 & 2000 & - \\
\hline $\mathrm{V}$ & $<0,2$ & - & $<0,2$ & 2,21 & 1 & 100 \\
\hline $\mathrm{Mn}$ & $130000 \pm 14000$ & 1,2 & $109000 \pm 10000$ & 46,2 & 5 & 500 \\
\hline $\mathrm{Fe}$ & $350 \pm 78$ & 87 & $<0,5$ & 0,52 & 500 & 1000 \\
\hline Co & $140 \pm 30$ & 16 & $12 \pm 1$ & 0,52 & 0,5 & 100 \\
\hline $\mathrm{Ni}$ & $92 \pm 19$ & 10 & $6,0 \pm 0,5$ & 5,6 & 0,3 & 100 \\
\hline $\mathrm{Zn}$ & $12000 \pm 1700$ & 1,4 & $11000 \pm 1000$ & 30,7 & 5 & 5000 \\
\hline $\mathrm{Cu}$ & $230 \pm 52$ & 6,8 & $18 \pm 1$ & 8,98 & 3 & 1000 \\
\hline $\mathrm{Ga}$ & $4,6 \pm 1$ & 11 & $<0,1$ & 0,66 & 0,1 & $\begin{array}{llll}- & & & \end{array}$ \\
\hline As & $8 \pm 1,9$ & 55 & $<0,6$ & 2,15 & 0,5 & 50 \\
\hline $\mathrm{Rb}$ & $16 \pm 1,6$ & 1,3 & $11 \pm 1$ & 2,06 & 1 & 100 \\
\hline $\mathrm{Sr}$ & $910 \pm 78$ & 1,2 & $760 \pm 75$ & 340 & 50 & 7000 \\
\hline Mo & $7,5 \pm 1,7$ & 27 & $<0,3$ & 5,5 & 1 & 250 \\
\hline $\mathrm{Cd}$ & $50 \pm 4$ & 1,2 & $34 \pm 3$ & 0,62 & 0,2 & 1 \\
\hline Cs & $7,5 \pm 1,0$ & 1,3 & $6,5 \pm 0,5$ & 0,65 & 0,05 & - \\
\hline $\mathrm{Ba}$ & $160 \pm 35$ & 12 & $8,0 \pm 0,6$ & 24,3 & 10 & 100 \\
\hline $\mathrm{La}$ & $370 \pm 39$ & 1,2 & $455 \pm 40$ & 0,3 & 0,3 & - \\
\hline $\mathrm{Ce}$ & $610 \pm 91$ & 1,2 & $890 \pm 85$ & 1 & 0,4 & - \\
\hline $\operatorname{Pr}$ & $62 \pm 9$ & 1,4 & $85 \pm 8$ & $\begin{array}{llll}- & & & \end{array}$ & 0,06 & $\begin{array}{llll}- & & & \end{array}$ \\
\hline $\mathrm{Nd}$ & $220 \pm 30$ & 1,3 & $280 \pm 25$ & - & 0,2 & - \\
\hline $\mathrm{Sm}$ & $51 \pm 9$ & 1,4 & $65 \pm 6$ & - & 0,03 & 24 \\
\hline $\mathrm{Eu}$ & $4,5 \pm 0,6$ & 1,2 & - & - & 0,01 & 300 \\
\hline $\mathrm{Gd}$ & $81 \pm 10$ & 1,3 & $100 \pm 10$ & $\begin{array}{lll}- & \\
\end{array}$ & 0,1 & - \\
\hline Dy & $81 \pm 9$ & 1,2 & $95 \pm 10$ & - & 0,04 & - \\
\hline Ho & $16,0 \pm 1,5$ & 1,2 & $19 \pm 2$ & - & 0,01 & - \\
\hline $\mathrm{Tm}$ & $6,5 \pm 0,6$ & 1,2 & $8,0 \pm 0,8$ & - & 0,008 & - \\
\hline $\mathrm{Yb}$ & $38 \pm 3$ & 1,2 & $53 \pm 5$ & - & 0,03 & - \\
\hline $\mathrm{Lu}$ & $5,5 \pm 0,6$ & 1,2 & $8,0 \pm 0,8$ & - & 0,002 & - \\
\hline $\operatorname{Re}$ & $1,7 \pm 0,3$ & 1,4 & $2,0 \pm 0,2$ & $\begin{array}{llll}- & & & \end{array}$ & $\begin{array}{llll}- & & & \end{array}$ & $\begin{array}{llll}- & & & \end{array}$ \\
\hline $\mathrm{Pb}$ & $105 \pm 24$ & 9 & $<0,01$ & 4,43 & 3 & 30 \\
\hline $\mathrm{U}$ & $1050 \pm 209$ & 1,4 & $4500 \pm 450$ & 1,76 & 0,1 & 15 \\
\hline
\end{tabular}

Примечание: $\bar{x} \pm S \bar{x}-$ среднее арифметическое содержание и СКО элементов; $C_{\text {max }} / C_{\min }-$ размах колебаний коничентрации элементов.

Note: $\bar{x} \pm S \bar{x}-$ arithmetic mean for the content and MSD of elements; $C_{m a x} / C_{\min }-$ fluctuation amplitude of elements concentrations.

Сравнительные данные содержания химических элементов в воде штольни 504 относительно среднего содержания в подземных водах аридного климата и эталонной воды представлены в следующем убывающем ряду (индекс - кратность превышения среднего содержания):

- $\mathrm{Be}_{6200}>\mathrm{Mn}_{2800}>\mathrm{La}_{1200}>\mathrm{Ce}_{600}>\mathrm{U}_{600}>\mathrm{Zn}_{390}>\mathrm{Al}_{130}>$ $\mathrm{Cu}_{100}>\mathrm{Cd}_{80}>\mathrm{Pb}_{20}>\mathrm{Cs}_{10}>\mathrm{Li}_{10}>\mathrm{Rb}_{8}>\mathrm{Ga}_{7}>\mathrm{Sr}_{3}$ (относительно среднего содержания в подземных водах аридного климата);

- $\mathrm{Mn}_{26000}>\mathrm{U}_{10000}>\mathrm{Be}_{5600}>\mathrm{Lu}_{2700}>\mathrm{Zn}_{2400}>\mathrm{Dy}_{2000}>\mathrm{Sm}_{1700}$ $>\mathrm{Ho}_{1600}>\mathrm{Ce}_{1500}>\mathrm{La}, \mathrm{Yb}_{1200}>\mathrm{Nd}_{1100}>\mathrm{Pr}_{1000}>\mathrm{Tm}, \mathrm{Gd}_{800}>$ $\mathrm{Eu}_{400}>\mathrm{Ni}_{300}>\mathrm{Co}_{280}>\mathrm{Cd}_{250}>\mathrm{Al}_{190}>\mathrm{Cs}_{150}>\mathrm{Li}_{110}>\mathrm{Cu}_{77}>$ $\mathrm{Ga}_{48}>\mathrm{Pb}_{35}>\mathrm{Sr}_{18}>\mathrm{As}_{16}>\mathrm{Ba}_{2} \mathrm{Rb}_{16}>\mathrm{Ca}_{14}>\mathrm{Mo}_{8}>\mathrm{Mg}_{7}$ (относительно среднего содержание эталонной пресной воды)

Из убывающего ряда видно, что концентрация большинства исследуемых элементов значительно превыша- ет показатели кларка в подземных водах аридного климата и эталонной пресной воды. Содержание таких элементов, как $\mathrm{Na}, \mathrm{Mg}, \mathrm{K}, \mathrm{Ca}, \mathrm{V}$ и $\mathrm{Fe}$, находится на уровне кларка подземных вод аридного климата.

Кратность превышения предельно-допустимых концентраций химических элементов в воде представлена в ряду убывания (индекс - кратность превышения ПДК):

$$
\mathrm{Be}_{2800}>\mathrm{Mn}_{260}>\mathrm{Al}_{76}>\mathrm{U}_{70}>\mathrm{Cd}{ }_{50}>\mathrm{Zn}_{12}>\mathrm{Li}_{11}>\mathrm{Pb}_{3}>\mathrm{Sm}_{2} .
$$

Из данного ряда видно, что максимальный показатель превышения ПДК характерен для Ве (в 2800 раз). Следует отметить, что содержание таких элементов, как $\mathrm{Mg}, \mathrm{Fe}, \mathrm{Co}$, Ni и Ba, в воде находится на уровне 1 ПДК.

В воде штольни 504 выявлено аномально высокое содержание редкоземельных элементов, превышающих показатель кларка от сотни до тысячи раз. Для $\mathrm{Sm}$ отмечено превышение ПДК в воде в 2 раза. 


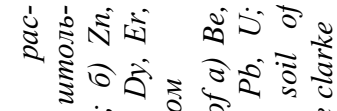

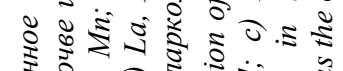

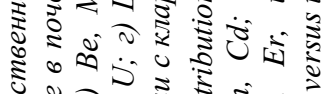

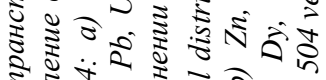

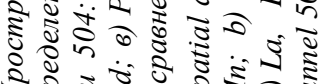

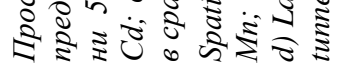

$\dot{m} \quad \dot{m}$
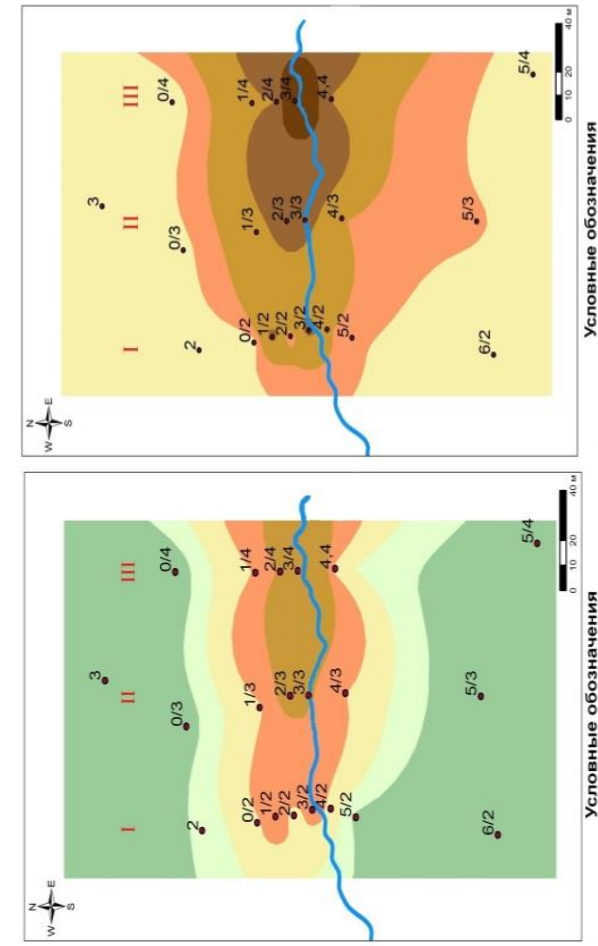
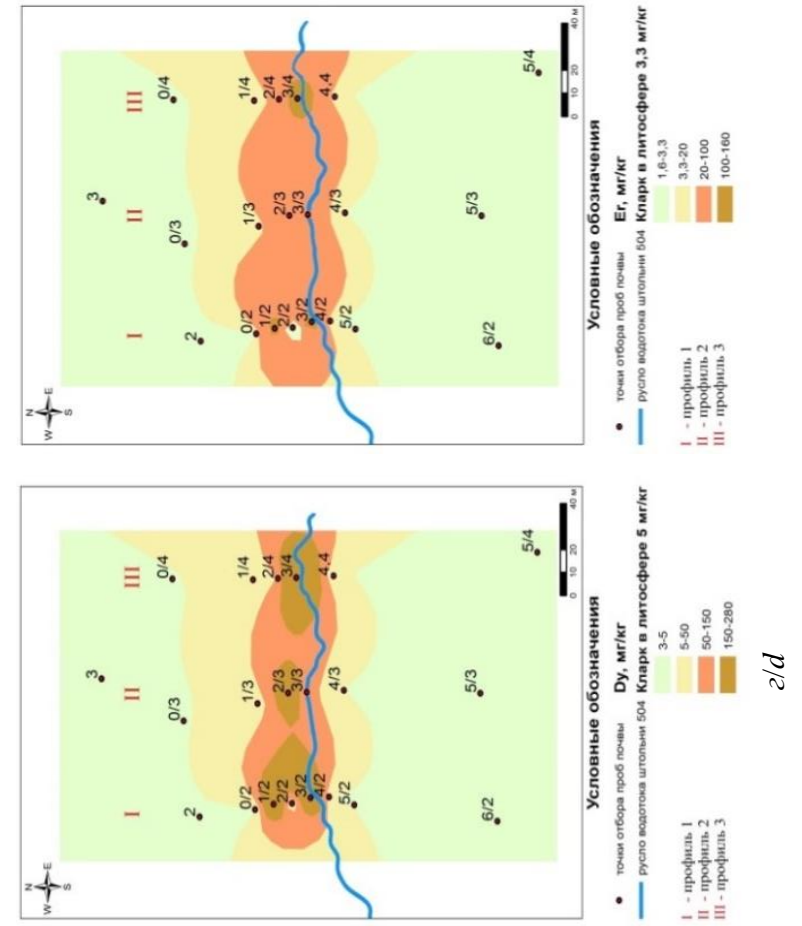

III

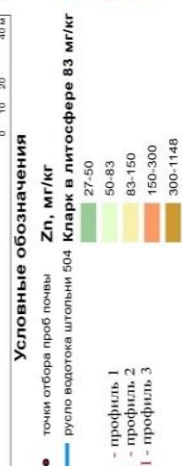

ธี

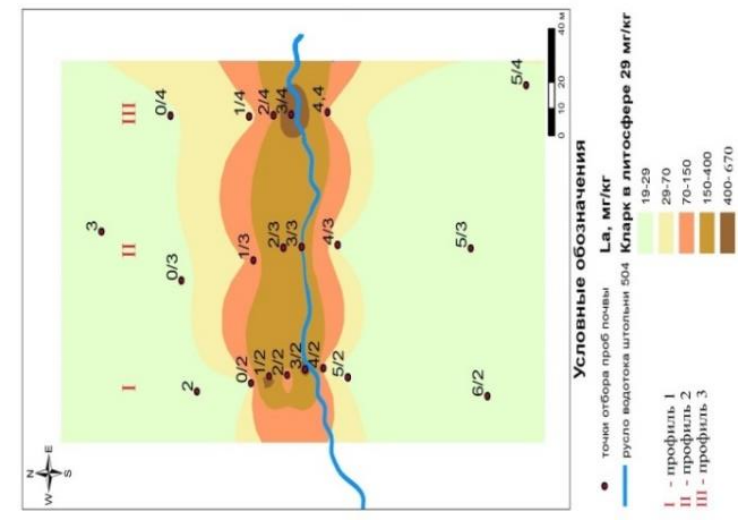

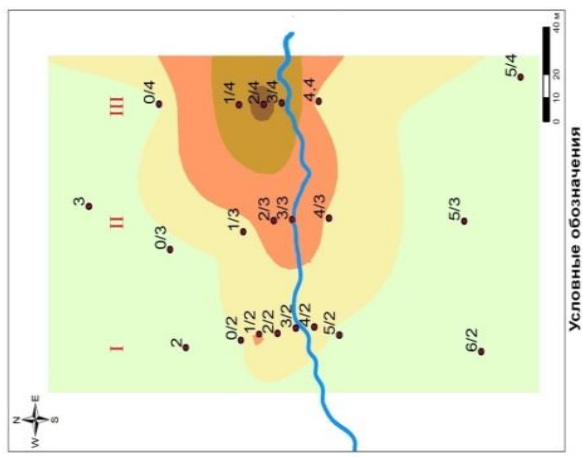
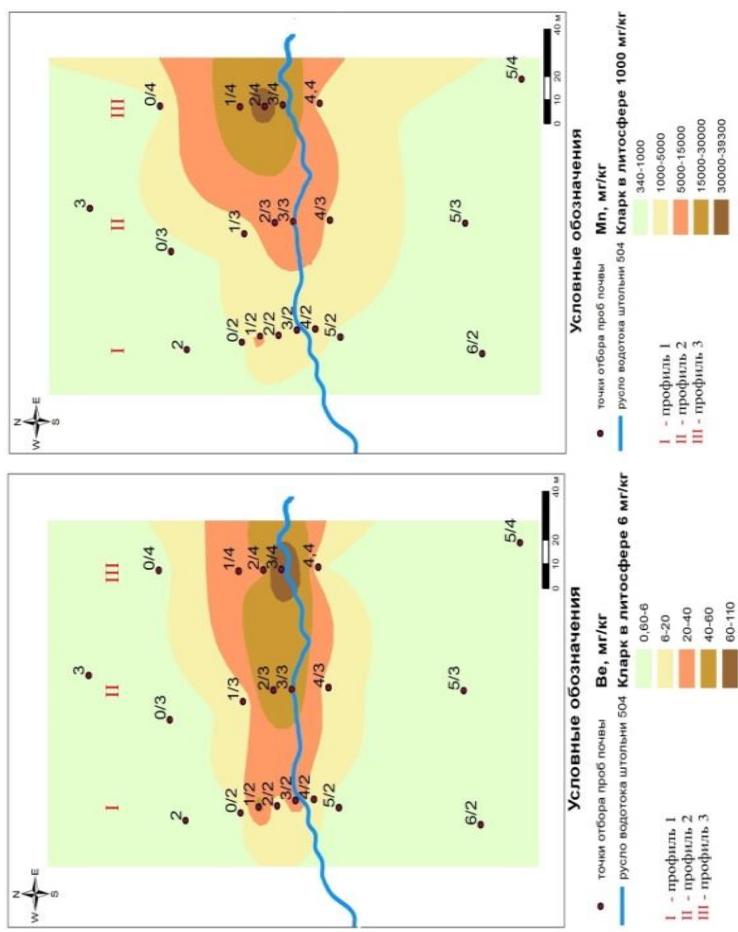

$\frac{2}{2}$

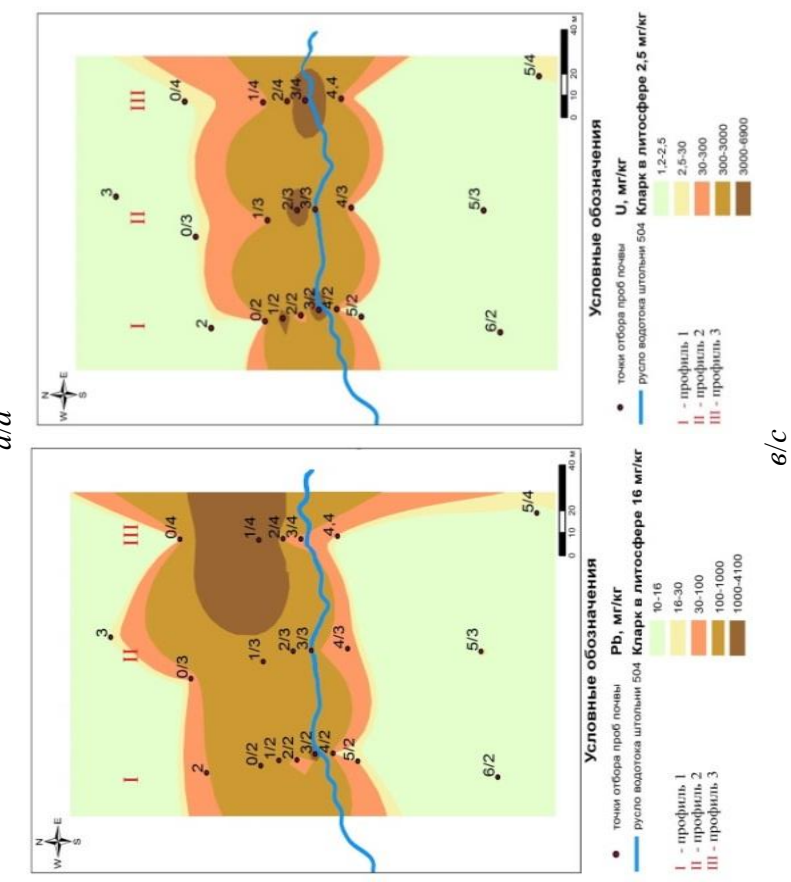


Для воды штольни 504 характерно преобладание группы легких РЗЭ с ярко выраженной церийлантановой специализацией. Исходя из представленных данных, можно сделать вывод, что породообразующие минералы (полевые шпаты, биотит, глинистые и фосфатные минералы) исследуемого участка накапливают в себе легкие РЗЭ, которые в дальнейшем при естественном вымывании попадают в водную среду [21-26].

Таким образом, можно сделать вывод, что в воде штольни 504 выявлены аномально высокие концентрации большинства химических элементов.

Следует отметить, что для исследуемого объекта выявлены благоприятные геохимические условия для миграции химических элементов, в частности кислые значения рН воды $(<5,5)$.

\section{Исследование пространственного распределения} элементов в грунте припортального участка штольни 504

Накопление тяжелых металлов и токсичных элементов в почве является показателем ее загрязненности, при этом она может быть и источником вторичного загрязнения среды. Оценка содержания исследуемых химических элементов в почве на припортальном участке штольни 504 выполнена относительно кларка литосферы и ПДК [27].

Для некоторых элементов, которые присутствуют в аномальном количестве, построены карты-схемы пространственного распределения элементов (рис. 3).

Анализ данных карт показал, что повышенное содержание элементов в почве локализовано непосредственно в местах водотока, т. е. в русле. Все эти данные подтверждают, что источником поступления элементов в почву служит непосредственно водная среда Пространственное распределение исследуемых элементов в почве штольни 504 неоднородно, большая часть элементов концентрируется севернее русла водотока. По ширине профиля уровень содержания большинства элементов в почве на удалении 20 м от русла уменьшается в десятки раз. По длине (расстояние от 50 до 150 м от портала штольни) профиля большая часть аномальных элементов, обнаруженных в воде, постепенно осаждается в почве. Необходимо отметить, что концентрация $\mathrm{Al}$ и $\mathrm{Li}$ в почве ниже значения кларка литосферы, осаждение данных элементов в почве возможно за пределами участка исследования.

Полученные данные по пространственному распределению элементов в почве штольни 504 позволяют условно выделить участки с относительным содержанием в них элементов. Первый участок, где содержание элементов в почве незначительно и находится на уровне кларка либо ниже этого значения (условно фоновый участок). Второй участок с повышенным содержанием элементов (условно загрязненный участок), подверженный влиянию штольневых водотоков, где концентрации элементов превышают предельно допустимые уровни (рис. 4).

Среднее содержание элементов на фоновых и загрязненных участках представлено в табл. 2.

Необходимо отметить, что среднее содержание свинца и урана в некоторых фоновых точках превышает показатель кларка в 2 раза. Превышения пре- дельно допустимых концентрации элементов на исследуемом фоновом участке почвы не обнаружено.

Как видно из таблицы, среднее содержание большинства элементов в почве штольни 504, отобранных на загрязненном участке, характеризуется значительными пределами колебаний, в особенности для $\mathrm{Cu}, \mathrm{Pb}$ и $\mathrm{U}$.

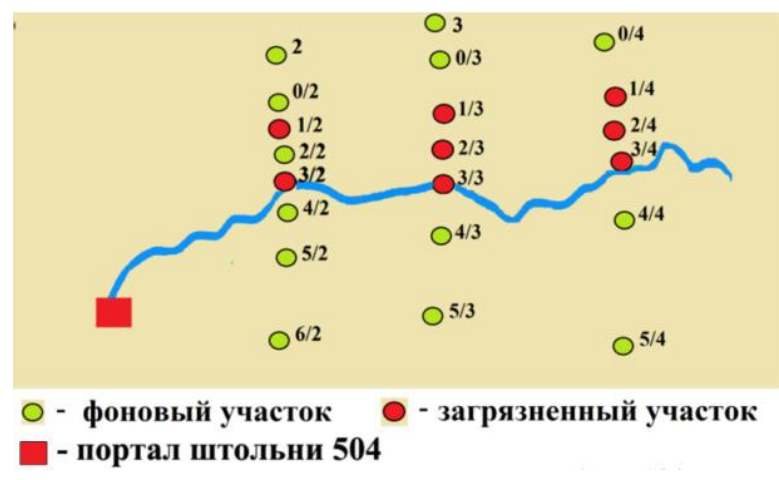

Рис. 4. Схема пространственного распределения элементов в почве итольни 504

Fig. 4. Scheme of spatial distribution of elements concentrations in soil of tunnel 504

На загрязненном участке штольни 504 проведен сравнительный анализ содержания химических элементов в почве с показателями кларка и ПДК для почв. Зависимость превышения концентрации элементов на загрязненном участке значения кларка представлена в следующем убывающем ряду (индекс - кратность превышения кларка):

$$
\mathrm{U}_{1000}>\mathrm{Pb}_{50}>\mathrm{Cd}_{25}>\mathrm{Cu}_{20}>\mathrm{Mn}_{15}>\mathrm{Be}_{8}>\mathrm{Mo}, \mathrm{Zn}_{5}>\mathrm{Cs}_{2} .
$$

Из убывающего ряда видно, что превышение значения кларка для урана на загрязненных участках штольни 504 на порядки выше, чем у остальных элементов. Также незначительное превышение значения кларка на загрязненном участке выявлено у цезия.

Сравнение полученных данных на загрязненных участках со значением предельно-допустимых концентраций химических элементов для почвы выявило превышение у $\mathrm{Pb}$ (26 ПДК), Mn и Сu (9 ПДК). Содержание таких элементов, как $\mathrm{Be}, \mathrm{Zn}$ и $\mathrm{Cd}$, на исследуемом загрязненном участке находится на уровне 1 ПДК в почве.

Данные по содержанию исследуемых РЗЭ в почве на загрязненном участке относительно кларка в почвах мира представлено в следующем убывающем ряду (индекс - кратность превышения кларка):

$\mathrm{Tm}_{40}>\mathrm{Dy}, \mathrm{Er}_{25}>\mathrm{Gd}, \mathrm{Sm}, \mathrm{Lu}_{1} \mathrm{Ho}_{15}>\mathrm{La}, \mathrm{Ce}, \mathrm{Pr}, \mathrm{Nd}, \mathrm{Eu}_{10}$.

Из убывающего ряда видно, что превышение показателя кларка в почве штольни 504 наиболее выражено для группы тяжелых РЗЭ.

\section{Исследование содержания элементов}

в растениях водотока штольни 504

В русле водотока 504 штольни в основном произрастают такие доминантные виды растений, как тростник, осока, вейник, которые относятся к гидрофитам, и караган из группы мезофитов. По мере удаления от русла водотока в основном произрастают ксерофитные растения (менее влаголюбивые) - ко- 
выль и полынь. При этом ареал произрастания большинства исследуемых гидро- и мезофитных растений расположен к середине профиля, в местах повышенного содержания в воде химических элементов.

Таблица 2. Среднее содержание химических элементов в почве штольни 504, мг/кг

Table 2. Average content of chemical elements in acid soil extracts from tunnel 504, $\mathrm{mg} / \mathrm{kg}$

\begin{tabular}{|c|c|c|c|c|c|c|}
\hline \multirow{2}{*}{$\begin{array}{l}\text { Элементы } \\
\text { Elements }\end{array}$} & \multicolumn{2}{|c|}{$\begin{array}{c}\text { Фоновый участок } \\
\text { Background area (n=13) }\end{array}$} & \multicolumn{2}{|c|}{$\begin{array}{c}\text { Загрязненный участок } \\
\text { Contaminated area }(n=8)\end{array}$} & \multirow{2}{*}{$\begin{array}{c}\text { Кларк в почвах мира } \\
\text { Clarke in soil worldwide [26] }\end{array}$} & \multirow{2}{*}{$\begin{array}{c}\text { ПДК } \\
\text { МРС }[26]\end{array}$} \\
\hline & $\bar{x} \pm S \bar{x}$ & $\mathrm{C}_{\text {max }} / \mathrm{C}_{\text {min }}$ & $\bar{x} \pm S \bar{x}$ & $\mathrm{C}_{\max } / \mathrm{C}_{\min }$ & & \\
\hline $\mathrm{Be}$ & $3,0 \pm 0,1$ & 1,5 & $46 \pm 1$ & 4,0 & 6 & 50 \\
\hline $\mathrm{Al}$ & $10900 \pm 70$ & 12 & $24000 \pm 70$ & 5,5 & 80500 & - \\
\hline $\mathrm{Mn}$ & $790 \pm 6$ & 7,3 & $14000 \pm 60$ & 30 & 1000 & 1500 \\
\hline $\mathrm{Cu}$ & $13,0 \pm 0,2$ & 4,0 & $960 \pm 8$ & 100 & 47 & 100 \\
\hline $\mathrm{Zn}$ & $65 \pm 1$ & 5,5 & $380 \pm 3$ & 8,5 & 83 & 300 \\
\hline Mo & $1,6 \pm 0,1$ & 3,1 & $6,0 \pm 0,1$ & 3,5 & 1,1 & $\begin{array}{lll}- & \\
-\end{array}$ \\
\hline $\mathrm{Cd}$ & $0,60 \pm 0,02$ & 3,0 & $3,2 \pm 0,1$ & 7,8 & 0,13 & 3 \\
\hline Cs & $1,50 \pm 0,01$ & 1,7 & $6,3 \pm 0,1$ & 11 & 3,7 & $\begin{array}{lll}- & & \\
\end{array}$ \\
\hline $\mathrm{La}$ & $26 \pm 1$ & 2,6 & $300 \pm 3$ & 12 & 29 & - \\
\hline $\mathrm{Ce}$ & $51 \pm 1$ & 2,2 & $800 \pm 7$ & 17 & 70 & - \\
\hline $\operatorname{Pr}$ & $5,8 \pm 0,1$ & 2,1 & $100 \pm 1$ & 18 & 9 & - \\
\hline $\mathrm{Nd}$ & $22 \pm 1$ & 2,5 & $420 \pm 3$ & 20 & 37 & - \\
\hline $\mathrm{Sm}$ & $4,0 \pm 0,1$ & 2,3 & $120 \pm 1$ & 26 & 8 & $\begin{array}{lll}- & \\
-\end{array}$ \\
\hline $\mathrm{Eu}$ & $0,50 \pm 0,01$ & 2,5 & $10,0 \pm 0,1$ & 24 & 1,3 & $\begin{array}{llll}- & \\
\end{array}$ \\
\hline $\mathrm{Gd}$ & $4,8 \pm 0,1$ & 3,3 & $130 \pm 1$ & 18 & 8 & $\begin{array}{llll}- & & & \end{array}$ \\
\hline Dy & $4,0 \pm 0,1$ & 4,0 & $130 \pm 1$ & 20 & 5 & - \\
\hline Ho & $0,80 \pm 0,01$ & 4,0 & $24,0 \pm 0,2$ & 19 & 1,7 & $\begin{array}{llll}- & & & \end{array}$ \\
\hline $\mathrm{Er}$ & $2,7 \pm 0,1$ & 3,7 & $77 \pm 1$ & 20 & 3,3 & - \\
\hline $\mathrm{Tm}$ & $0,40 \pm 0,01$ & 4,0 & $11,0 \pm 0,1$ & 18 & 0,27 & - \\
\hline $\mathrm{Lu}$ & $0,30 \pm 0,01$ & 3,7 & $12,0 \pm 0,1$ & 23 & 0,8 & $\begin{array}{llll}- & & & \end{array}$ \\
\hline $\mathrm{Pb}$ & $30 \pm 2$ & 9 & $840 \pm 2$ & 135 & 16 & 32 \\
\hline $\mathrm{U}$ & $5,0 \pm 0,3$ & 29 & $2700 \pm 20$ & 69 & 2,5 & - \\
\hline
\end{tabular}

Примечание: $\bar{x} \pm S \bar{x}$ - среднее содержание и СКО элементов; $C_{\text {max }} / C_{\text {min }}-$ размах колебаний концентрации элементов. Note: $\bar{x} \pm S \bar{x}$-average content and MSD of elements; $C_{\max } / C_{\min }$-fluctuation amplitude of elements concentrations.

Для сравнения взяты пробы растений, отобранных с условно фонового и загрязненного участков. В табл. 3 представлено среднее содержание элементов в сухой массе растений относительно их кларка растительности суши.

При сравнении полученных данных со значением кларка растительности суши выявлено превышение содержания в исследуемых видах растений таких элементов, как $\mathrm{Be}, \mathrm{Mn}, \mathrm{Cd}, \mathrm{Zn}, \mathrm{Pb}$ и U. Повышенное содержание данных элементов отмечено в исследуемых пробах воды и почвы.

Анализ данных таблицы показал, что из гидрофитных растений на загрязненном участке только осока накапливает повышенные концентрации $\mathrm{Cs}$, U и редкоземельных элементов. Среднее содержание Cs и исследуемых РЗЭ в осоке на загрязненном участке превышает их фоновые концентрации в десятки раз, а $\mathrm{U}$ - в сотни раз (табл. 3).

Мезофиты (карагана), произрастающие на загрязненном участке, накапливают относительно фонового участка в повышенных концентрациях такие элементы, как $\mathrm{Be}, \mathrm{Cd}, \mathrm{Pb}$ и U. Так, в карагане среднее содержание $\mathrm{Be}, \mathrm{Cd}, \mathrm{Pb}$ на загрязненном участке превышает значение фона в 40-50 раз, тогда как U - в тысячу раз. Необходимо также отметить, что концентрация $\mathrm{Be}$, $\mathrm{Cd}$ и $\mathrm{U}$ в карагане на фоновом участке находилась на уровне пределов обнаружения.

В ксерофитных растениях накапливаются те же элементы, что и в мезофитах, $-\mathrm{Be}, \mathrm{Pb}$ и $\mathrm{U}$. Так, в полыни среднее содержание $\mathrm{Be}$ и $\mathrm{Pb}$ на загрязненном участке превышает их фоновые концентрации в
30-60 раз, тогда как концентрация урана - в 800 раз. Следует отметить, что в ковыли концентрация Ве и $\mathrm{Pb}$ на сравниваемых участках меняется незначительно, а содержание урана превышает фон в 350 раз (табл. 3).

Для оценки накопления химических элементов в растениях был использован коэффициент биологического поглощения, который представляет собой отношение концентрации химических элементов в сухой массе растения к его содержанию в почве [29]. По значению коэффициента в вышеуказанных видах растений накопление элементов слабое $(0,1-1)$.

В отобранных пробах растений на загрязненном участке замечено повышенное содержание $\mathrm{Be}, \mathrm{Cd}, \mathrm{Cs}$, $\mathrm{Pb}, \mathrm{U}$ и РЗЭ. Для большинства видов растений штольни 504 выявлено максимальное накопление урана, превышающее их фоновые значения в сотни и тысячу раз. Таким образом, химический состав растений штольни 504 отражает элементный состав почвы.

Так, содержание элементов в большинстве видов растений (осока, карагана, ковыль и полынь) зависела от места его произрастания - на загрязнённом участке почвы или на фоновом. Однако концентрация исследуемых элементов в таких видах растений, как тростник и вейник, на сравниваемых участках менялась незначительно, что, видимо, обусловлено наличием физиолого-биохимических механизмов, препятствующих их поступлению. Как показали результаты элементного анализа, процесс накопления химических элементов в представленных видах растений зависит от физиологических особенностей растений и их отношения к влажности. 


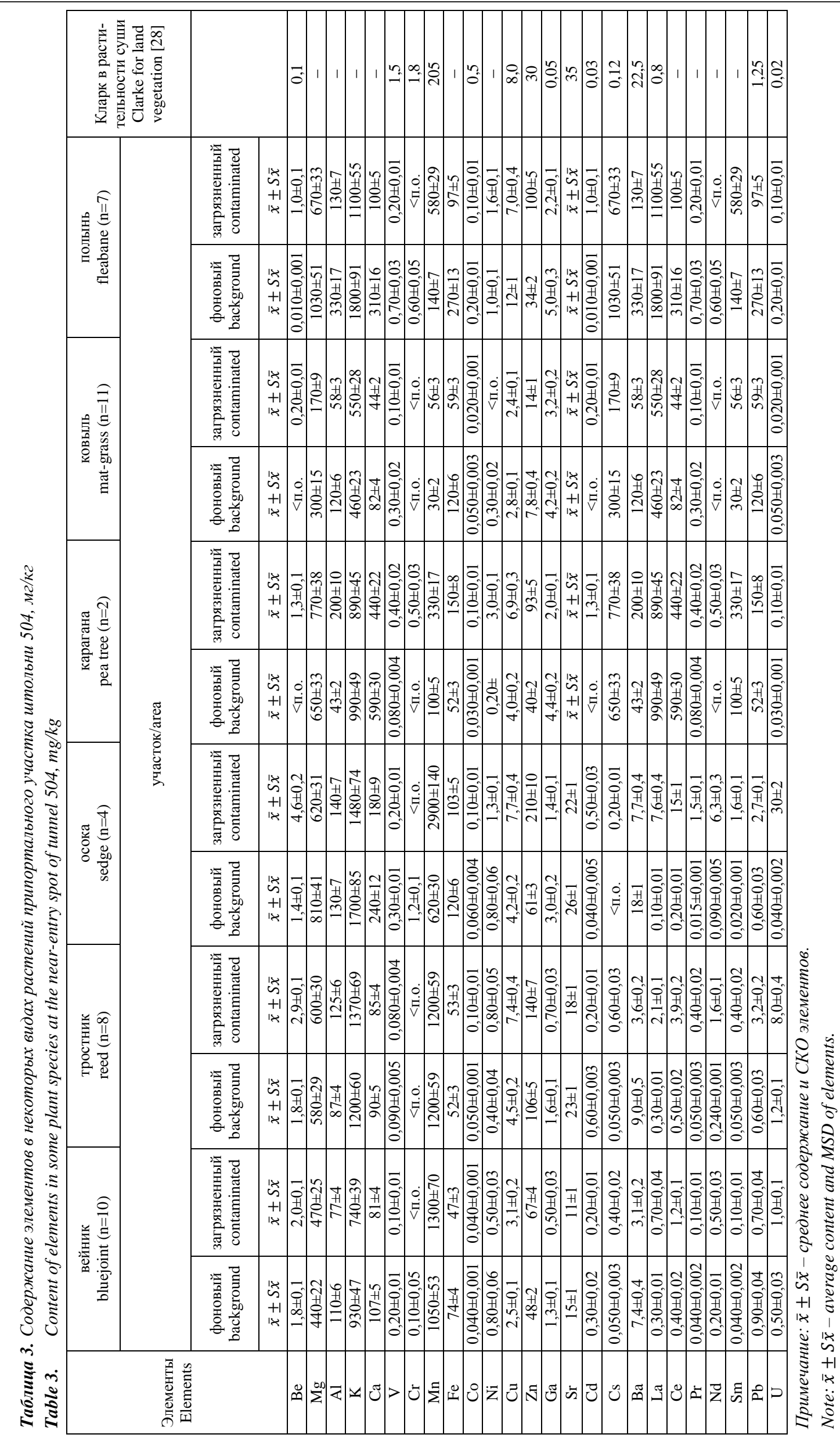




\section{Заключение}

Исходя из вышеизложенного, можно сделать вывод, что пространственное распределение элементов на площадке штольни 504 связано, прежде всего, с выносом химических элементов штольневыми водами. В воде штольни 504 выявлено порядка десяти элементов, превышающих значения кларка и предельно допустимые уровни. Концентрация большинства элементов в почве на удалении 20 м от русла водотока уменьшается в десятки раз. В растениях штольни 504 отмечено накопление тех же элементов, что в почве и в воде. Для

\section{СПИСОК ЛИТЕРАТУРЫ}

1. Акчурин И.А. Семипалатинский ядерный полигон: создание становление, деятельность. - М.: М-во обороны Российской Федерации, 12 Центральный науч.- исслед. ин-т, 2007. - 225 с.

2. Логачев В.А. Ядерные испытания СССР: современное радиоэкологическое состояние полигона. - М.: ИздАТ, 2002. - 639 с.

3. Subbotin S.B., Dubasov Yu.V. Radioactive contamination of water of the Degelen mountain massif // Radiokhimiya. - 2013. V. 55, - № 6. - P. 561-567.

4. Aidarkhanova A.K., Lukashenko S.N. Investigation of character of distribution of radioactive contamination in the "water-sediments system of Semipalatinsk Test Site and adjacent territories // ENVIRA 2015 International Conference proceedings. - Greece, 2015. - P. 295.

5. Геохимический фон СИП. Микроэлементы в почвах участков, прилегающих к горному массиву Дегелен» / А.А. Амиров, С.Н. Лукашенко, С.Б. Субботин, В.Д. Кириллов, В.П. Солодухин, Н.М. Бердинова, Д.А. Желтов // Актуальные вопросы радиоэкологии Казахстана: Вып. 2 Сборник трудов Института радиационной безопасности и экологии за 2007-2009 гг. Павлодар: Дом печати, 2010. - С. 451-460.

6. Торопов А.С., Рихванов Л.П. Есильканов Г.М. Пространственное распределение форм нахождения радионуклидов в воде ручья Карабулак Семипалатинского испытательного полигона // Известия Томского политехнического университета. Инжиниринг георесурсов. - 2017. - Т. 328. - № 12. - С. 6-15. URL: http://izvestiya.tpu.ru/archive/article/view/1954 (дата обращения 13.09.2019).

7. Отчет «Программа работ по гидрогеологическому обследованию горного массива Дегелен после закрытия штолен (договор HDTRA 0023/2 от 1 марта 1999 года)». - Курчатов: «Национальный ядерный центр Республики Казахстан», «Институт геофизических исследований», 1999. - 72 с.

8. ГОСТ Р 51592-2000. Вода. Общие требования к отбору проб. М.: Изд-во стандартов, 2000. - 8 с.

9. Отбор проб объектов окружающей среды и биосубстратов для элементного анализа: РИ 03-02-07 (А). - Курчатов: ИРБЭ НЯЦ РК, 2015. - $18 \mathrm{c}$.

10. ГОСТ 26449.1-85. Установки дистилляционные опреснительные стационарные. Методы анализа соленых вод. - М.: Изд-во стандартов, 2003. - $101 \mathrm{c}$.

11. Определение содержания токсичных элементов в пищевых продуктах и продовольственном сырье. Методика автоклавной пробоподготовки: методические указания 4.1.985-00. - М. Минздрав России, 2000. - 19 с.

12. Подготовка проб для элементного анализа методом автоклавного разложения. Рабочая инструкция - РИ 03-02-03 (А). Курчатов: Центр радиоэкологических исследований, филиал ИРБЭ НЯЦ РК, 2014. - 12 с

13. Подготовка проб объектов окружающей среды и биологического субстрата для элементного анализа. Рабочая инструкция - РИ 03-02-08 (А). - Курчатов: Филиал «Институт радиационной безопасности и экологии» РГП Национальный ядерный центр, 2015. - 15 c.

14. Water quality. Application of inductively coupled plasma mass spectrometry (ICP-MS) P. 2: Determination of 62 elements. ISO 17294-2:2003 (E). - Switzerland, 2003. - 30 p. URL https://www.iso.org/standard/36127.html (дата обращения 13.09.2019). большинства видов растений штольни 504 выявлено содержание урана, превышающее его фоновое значение в сотни и тысячи раз. Как было отмечено выше, для исследуемого объекта выявлены благоприятные геохимические условия для миграции химических элементов, в частности кислые значения $\mathrm{pH}$ воды $(<5,5)$.

Авторы статьи выражают благодарность всем сотрудникам Института Радиационной Безопасности и Экологии НЯЦ РК за оказанную помощьв в организаичи полевых и лабораторных работ.

15. Берестнева О.Г., Муратова Е.А., Уразаев А.М. Компьютерный анализ данных. - Томск: Изд-во ТПУ, 2003. - 204 с

16. Плохинский Н.А. Биометрия. - М.: МГУ, 1970. - 367 с.

17. Лукашенко С.Н., Амиров А.А. Факторы формирования загрязнения тяжелыми металлами припортальных участков площадки «Дегелен». Актуальные вопросы радиоэкологии Казахстана. Вып. 3. Сборник трудов национального ядерного центра РК за 2011 / под рук. Лукашенко С. Н. - Павлодар: Дом печати, 2011. - С. 295-314.

18. Шварцев С.Л. Гидрогеохимия зоны гипергенеза. - М.: Недра, 1998. $-354 \mathrm{c}$

19. Bernd Markcrt. Inorganic chemical fingerprinting of the environment: «reference freshwater» - a useful tool for comparison and harmonization of analytical data in freshwater chemistry // Fresenius' Journal of Analytical Chemistry. - 1994. V. 349. - Iss. 10-11. - P. 697-702. URL: https://link.springer.com/article/10.1007/BF00325642 (дата обращения 12.02.2020).

20. Санитарно-эпидемиологические требования к водоисточникам, местам водозабора для хозяйственно-питьевых целей, хозяйственно-питьевому водоснабжению и местам культурнобытового водопользования и безопасности водных объектов: утв. постановлением Правительством Республики Казахстан от 18 января 2012 года № 104

21. Чудаев О.В., Чудаева В.А. Микроэлементы и элементы редкоземельной группы в минеральных водах Приморья // Геология и горное дело в Приморье прошлом, настоящем и будущем. Владивосток: Дальнаука, 2000. - С. 93-96.

22. Seasonal and spatial variations in rare earth elements and yttrium of dissolved load in the middle, lower reaches and estuary of the Minjiang River, southeastern China / Xuxu Zhu, Aiguo Gao, Jianjie Lin, Xing Jian, Yufeng Yang, Yanpo Zhang, Yuting Hou, Songbai Gong // Journal of Oceanology and Limnology. - 2018. V. 36. - Iss. 3. - P. 700-716. URL: https://link.springer.com/article/10.1007/s00343-018-6207-9 (дата обращения 13.09.2019)

23. Geochemical behaviour of rare earth elements (REE) along a river reach receiving inputs of acid mine drainage / M. Olías, C.R. Cánovas, M.D. Basallote, A. Lozano // Chemical Geology. 2018. - V. 493. - P. 468-477. URL: https://www. sciencedirect.com/science/article/abs/pii/S0009254118303310 (дата обращения 13.09.2019).

24. Rare earth element patterns as process indicators at the water-solid interface of a post-mining area / A. Grawunder, M. Lonschinski, M. Händel, S. Wagner, D. Merten, D. Mirgorodsky, G. Büchel // Applied Geochemistry. - 2018. - V. 96. - P. 138-154. URL: https://www.sciencedirect.com/science/article/pii/S088329271830 0957 (дата обращения 13.09.2019).

25. Eker C.S., Kiliç E.D. Geochemistry of Coruh River Bed Sediments in NE Turkey: implications in weathering-sedimentary cycle, provenance, and metal pollution // Geochemistry International. 2018. - V. 56. - Iss. 6. - P. 579-600. URL: https://link.springer.com/article/10.1134/S0016702918060095 (дата обращения 13.09.2019).

26. Sojka M., Siepak M., Pietrewicz K. Concentration of Rare Earth Elements in surface water and bottom sediments in Lake Wadąg, Poland // Journal of Elementology. - 2018. - V. 24 (1). - P. 125140. URL: http://jsite.uwm.edu.pl/articles/view/1648/ (дата обращения 13.09.2019). 
27. Kloke A. Richwerte 80, Orientierungsdaten fur tolerier bare Gesamtgehalteeinger Elememte in Kulturboden // Metteilunger VDLUFA. - 1980. - H. 1-3. - S. 9-11.

28. Добровольский В.В. Основы биогеохимии. - М.: ИЦ «Академия», 2003. $-400 \mathrm{c}$.

\section{Информация об авторах}

Шакенов Е.3., магистр биологии, инженер Института радиационной безопасности и экологии.

Дюсембаева M.T., кандидат биологических наук, начальник лаборатории элементного анализа Института радиационной безопасности и экологии.

Лукашенко С.H., доктор биологических наук, главный научный сотрудник лаборатории радиохимии и аналитической химии Всероссийского научно-исследовательского института радиологии и агроэкологии.

Teмиржанова A.E., инженер Института радиационной безопасности и экологии.

Есильканов Г.М., инженер Института радиационной безопасности и экологии.

Мухамедияров Н.Ж., инженер Института радиационной безопасности и экологии. 
UDC 661.879.1:622.258.4:551.49:539.16

\title{
SPATIAL DISTRIBUTION OF CHEMICAL ELEMENTS IN THE STREAMFLOW OF TUNNEL 504 AT «DEGELEN» SITE
}

\author{
Yerbol Z. Shakenov', \\ shakenov@nnc.kz
}

\author{
Madina T. Dyusembayeva1, \\ koigeldinova@nnc.kz
}

Sergey N. Lukashenko², lukashenko.1962@mail.ru

\author{
Aray Ye. Temirzahnova ${ }^{1}$, \\ temirzhanova@nnc.kz
}

Gani M. Yesilkanov 1 , al-g_007@mail.ru

\author{
Nurlan Zh. Mukhamediyarov'1, \\ mukhamediyarov@nnc.kz \\ 1 Institute of Radiation Safety and Ecology, \\ 2, Beibit atom street, Kurchatov, 071100, Kazakhstan. \\ 2 Russian Scientific Research Institute of Radiobiology and Agroecology, \\ 109 km, Kiev highway, Obninsk, 249032, Russia.
}

Relevance of the research is caused by the necessity of obtaining up-to-date data on concentrations of chemical elements in the "watersoil-plant» system on the near-entry spot of tunnel 504 of «Degelen» site at the former Semipalatinsk Test Site. During flooding in spring, elements may be carried out beyond tunnel 504.

The main aim of the research is to study spatial distribution of chemical elements in the "water-soil-plant» system in the streamflow of tunnel 504. To achieve this goal, the following tasks were set: 1) determine concentration levels of chemical elements in water; 2) study concentration levels of chemical elements in soil; 3) identify features of chemical elements accumulation in plants of tunnel 504.

Methods. The ultimate composition of water was determined by inductively-coupled plasma mass-spectrometry (Elan 9000 «Perkin Elmer SCIEX»), inductively-coupled plasma atomic emission spectrometry («iCAP 6300 Duo» Thermo Scientific). The analysis of such indicators as total mineralization, the content of sulfates, hydrocarbonates, chlorides, calcium, magnesium and sodium was carried out using titrimetric, colorimetric, potentiometric techniques in accordance with GOST.

Results. The analysis of the data obtained for water showed a high content of such elements as $\mathrm{Li}, \mathrm{Be}, \mathrm{Al}, \mathrm{Mn}, \mathrm{Zn}, \mathrm{Rb}, \mathrm{Sr}, \mathrm{Cd}, \mathrm{Cs}, \mathrm{La}, \mathrm{Ce}$, $U$ the average content of which exceeds the clarke several times for groundwater of the arid climate (sulfate water). The excess of maximum permissible levels of such elements as Be (2800 MPC), Mn (260 MPC), Al (76 MPC), U (70 MPC) and Cd (50 MPC) has been registered for water. According to the latest data, the content of such elements as $\mathrm{Li}, \mathrm{Be}, \mathrm{Al}$ in water was found to increase by 2 times whereas that of $\mathrm{Co}, \mathrm{Ni}$ and $\mathrm{Cu}-$ by dozens of times. Spatial distribution of elements of interest in soil of tunnel 504 is non-uniform. Most of elements are concentrated in soil to the north of the streamflow bed. An elevated content of such elements as $\mathrm{Be}, \mathrm{Mn}, \mathrm{Cu}, \mathrm{Zn}, \mathrm{Mo}, \mathrm{Cd}, \mathrm{Cs}$, $\mathrm{Pb}$ and $\mathrm{U}$ was detected in this area exceeding the clarke of lithosphere. The high index of lithosphere clarke value excess was found for uranium concentration (1000 times). Comparison of findings for contaminated areas with values of maximum permissible concentrations of chemical elements in soil showed the excess for Pb (26 MPC), Mn and Cu (9 MPC). Chemical composition of water and soil of tunnel 504 is unique by the content of rare-earth elements. The average content of REE in water exceeds the clarke by thousand times in ground water of the arid climate and STS ground water. The excess of the maximum permissible concentration level of samarium was observed in water. Predominance of light REE is characteristic, with a pronounced cerium-lanthanum feature. This fact shows that metals in water originate from natural sources. For most plant species of tunnel 504 an elevated content of $\mathrm{Be}, \mathrm{Cd}, \mathrm{Cs}, \mathrm{Pb}, \mathrm{U}$ and a number of REE was detected in the contaminated area. Concentrations of elements of interest in such plant species as reed and bluejoint in areas being compared, varied insignificantly which is apparently attributed to some physiological and biochemical mechanisms that impede the intake. Based on the above, one can conclude that spatial distribution of elements at tunnel 504 is first of all related to chemical elements carried out by tunnel water. About ten elements exceeding clarke values and maximum permissible levels were detected in water of tunnel 504 .

\section{Key words:}

Semipalatinsk Test Site, «Degelen» site, tunnel, chemical elements, maximum permissible concentration, clarke, rare-earth elements.

The authors express thanks to all colleagues of the Institute of Radiation Safety and Ecology SRC RK for assistance in field and laboratory research. 


\section{REFERENCES}

1. Akchurin I.A. Semipalatinskiy yaderny poligon: sozdanie, stanovlenie, deyatelnost [Semipalatinsk nuclear test site: creation, formation, activity]. Moscow, Defense Ministry of the Russian Federation Publ., 2007. 225 p.

2. Logachev V.A. Yadernye ispytaniya SSSR: sovremennoe radioekologicheskoe sostoyanie poligona [Nuclear tests of the USSR: the current radioecological state of the landfill]. Moscow, IzdAT Publ. house, 2002. 639 p.

3. Subbotin S.B., Dubasov Yu.V. Radioactive contamination of water of the Degelen mountain massif. Radiokhimiya, 2013, vol. 55, no. 6, pp. 561-567.

4. Aidarkhanova A.K., Lukashenko S.N. Investigation of character of distribution of radioactive contamination in the «water-sediments» system of Semipalatinsk Test Site and adjacent territories. ENVIRA 2015 International Conference proceedings. Greece, 2015. pp. 295.

5. Amirov A.A., Lukashenko S.N., Subbotin S.B., Kirillov V.D., Solodukhin V.P., Berdinova N.M., Zheltov D.A. Geochemical background of STS. Trace elements in soils of sites adjacent to Degelen mountain massif. Topical Issues in Radioecology of $\mathrm{Ka}$ zakhstan. Proc. of the National Nuclear Center of the Republic of Kazakhstan for the 2007-2009. Ed. by S.N. Lukashenko. Pavlodar, Dom Pechati Publ., 2010. Vol. 2, Iss. 3, pp. 451-460.

6. Toropov A.S, Rikhvanov L.P, Yessilkanov G.M. Spatial distribution of radionuclide speciation in Karabulak stream of the Semipalatinsk Test Site. Bulletin of the Tomsk Polytechnic University. Geo Assets Engineering, 2017, vol. 328, no. 12, pp. 6-15. In Rus. Available at: http://izvestiya.tpu.ru/archive/article/view/1954 (accessed 13 September 2019).

7. Otchet «Programma rabot po gidrogeologicheskomu obsledovaniyu gornogo massiva Degelen posle zakrytiya shtolen (dogovor HDTRA 0023/2 ot 1 marta 1999 goda)» [Report «Work program for hydrogeological survey of the Degelen mountain massif after the adits were closed (contract HDTRA 0023/2 of March 1, 1999)»]. Kurchatov, «National Nuclear Centre of the Republic of Kazakhstan», «Institute of Geophysical Research» Publ., 1999. $72 \mathrm{p}$.

8. GOST R 51592-2000. Voda. Obshchie trebovaniya $k$ otboru prob [State Standard R 51592-2000. Water. General requirements for sampling.] Moscow, Standard publishing house, 2000. 8 p.

9. Otbor prob obyektov okruzhayushchey sredy i biosubstratov dlya elementnogo analiza: RI 03-02-07 (A) [Sampling of environmental objects and biosubstrates for elemental analysis: RI 03-02-07 (A)]. Kurchatov, IRSE NNC RK, 2015. 18 p

10. GOST 26449.1-85. Ustanovki distillyatsionnye opresnitelnye statsionarnye. Metody analiza solenykh vod [State Standard 26449.1-85. Stationary distillatory desalination units. Methods for analysis of salt waters]. Moscow, Standard publishing house, 2003. $101 \mathrm{p}$.

11. Opredelenie soderzhaniya toksichnykh elementov $v$ pishchevykh produktakh $i$ prodovolstvennom syrye. Metodika avtoklavnoy probopodgotovki: metodicheskie ukazaniya 4.1.985-00 [Determination of the content of toxic elements in food products and food raw materials. Autoclave sample preparation procedure: Methodological instructions 4.1.985-00]. Moscow, Ministry of Health of Russia Publ., 2000. 19 p.

12. Podgotovka prob dlya elementnogo analiza metodom avtoklavnogo razlozheniya. Rabochaya instruktsiya - RI 03-02-03 (A) [Preparation of samples for elemental analysis by autoclave decomposition. Work instruction - RI 03-02-03 (A)]. Kurchatov, Center for Radioecological Research, Branch of IRSE NNC RK Publ., 2014. 12 p.

13. Podgotovka prob obyektov okruzhayushchey sredy $i$ biologicheskogo substrata dlya elementnogo analiza. Rabochaya instruktsiya [Preparation of samples of environmental objects and biological substrate for elemental analysis. Work instruction RI 03-02-08 (A)]. Kurchatov, Branch of IRSE NNC RK Publ. 2015. 15 p.

14. Water quality. Application of inductively coupled plasma mass spectrometry (ICP-MS) P. 2: Determination of 62 elements. ISO $17294-2: 2003(E)$. Switzerland, 2003. 30 p. Available at: https://www.iso.org/standard/36127.html (accessed 13 September 2019).
15. Berestneva O.G., Muratova E.A., Urazaev A.M. Kompyuterny analiz dannykh [Computer data analysis]. Tomsk, TPU Publ. House, 2003. 204 p.

16. Plokhinsky N. A. Biometriya [Biometrics]. Moscow, Moscow State University Publ., 1970. 367 p.

17. Lukashenko S.N., Amirov A.A. Factors forming contamination with heavy metals at near-portal areas of Degelen site. Topical Issues in Radioecology of Kazakhstan. Proceedings of the National Nuclear Center of Kazakhstan for 2010. Pavlodar, Dom Pechati Publ., 2010. Iss. 3, vol. 2, 390 p.

18. Shvartsev S.L. Gidrogeokhimiya zony gipergeneza [Hydrogeochemistry of the zone of hypergenesis]. Moscow, Nedra Publ., 1998. $354 \mathrm{p}$.

19. Bernd Markcrt. Inorganic chemical fingerprinting of the environment: «reference freshwater» - a useful tool for comparison and harmonization of analytical data in freshwater chemistry. Fresenius' Journal of Analytical Chemistry, 1994, vol. 349, Iss. 10-11, pp. 697-702. Available at: https://link.springer.com/article/ 10.1007/BF00325642 (accessed 12 February 2020).

20. Sanitarno-epidemiologicheskie trebovaniya $k$ vodoistochnikam, mestam vodozabora dlya khozyaystvenno-pityevykh tseley, khozyaystvenno-pityevomu vodosnabzheniyu $i$ mestam kulturnobytovogo vodopolzovaniya i bezopasnosti vodnykh obyektov: utv. postanovleniem Pravitelstva Respubliki Kazakhstan ot 18 yanvarya 2012 goda № 104 Sanitary and epidemiological requirements for water sources, places of water intake for household and drinking purposes, domestic and drinking water supply, and places for cultural and domestic water use and the safety of water bodies: approved. Resolution of the Government of the Republic of Kazakhstan dated January 18, 2012 No. 104.

21. Chudaev O.V., Chudaeva V.A. Mikroelementy i elementy redkozemelnoy gruppy $v$ mineralnykh vodakh Primorya [Microelements and elements of the rare-earth group in the mineral waters of Primorye]. Vladivostok, Dalnauka Publ., 2000. pp. 93-96.

22. Xuxu Zhu, Aiguo Gao, Jianjie Lin, Xing Jian, Yufeng Yang, Yanpo Zhang, Yuting Hou, Songbai Gong. Seasonal and spatial variations in rare earth elements and yttrium of dissolved load in the middle, lower reaches and estuary of the Minjiang River, southeastern China. Journal of Oceanology and Limnology, 2018, vol. 36, Iss. 3, pp. 700-716. Available at: https://link.springer.com/ article/10.1007/s00343-018-6207-9 (accessed 13 September 2019).

23. Olías M., Cánovas C.R., Basallote M.D., Lozano A. Geochemical behaviour of rare earth elements (REE) along a river reach receiving inputs of acid mine drainage. Chemical Geology, 2018, vol. 493, pp. 468-477. Available at: https://www.sciencedirect.com/ science/article/abs/pii/S0009254118303310 (accessed 13 September 2019)

24. Grawunder A., Lonschinski M., Händel M., Wagner S., Merten D., Mirgorodsky D., Büchel G. Rare earth element patterns as process indicators at the water-solid interface of a post-mining area. Applied Geochemistry, 2018, vol. 96, pp. 138-154. Available at: https://www.sciencedirect.com/science/article/pii/S088329271830 0957 (accessed 13 September 2019).

25. Eker Ç.S., Kiliç E.D. Geochemistry of Çoruh River Bed Sediments in NE Turkey: Implications in Weathering-Sedimentary Cycle, Provenance, and Metal Pollution. Geochemistry International, 2018, vol. 56, Iss. 6, pp. 579-600. Available at: https://link.springer.com/article/10.1134/S0016702918060095 (accessed 13 September 2019).

26. Sojka M., Siepak M., Pietrewicz K. Concentration of Rare Earth Elements in surface water and bottom sediments in Lake Wadag, Poland. Journal of Elementology, 2018, vol. 24 (1), pp. 125-140. Available at: http://jsite.uwm.edu.pl/articles/view/1648/ (accessed 13 September 2019).

27. Kloke A. Richwerte 80, Orientierungsdaten fur tolerier bare Gesamtgehalteeinger Elememte in Kulturboden, Metteilunger. VDLUFA, 1980, no. 2, pp. 9-11.

28. Dobrovolsky V.V. Osnovy biogeokhimii [Fundamentals of biogeochemistry]. Moscow, Academiya Publ. Center, 2003. 400 p.

29. Perelman A.I. Geokhimiya landshafta [Landscape geochemistry]. Moscow, Astreya Publ., 2000. 715 p.

Received: 2 September 2020. 
Information about the authors

Yerbol Z. Shakenov, master of Biology, engineer, Institute of Radiation Safety and Ecology.

Madina T. Dyusembayeva, Cand. Sc., head of the ultimate analysis laboratory, Institute of Radiation Safety and Ecology.

Sergey N. Lukashenko, Dr. Sc., chief researcher, Russian Scientific Research Institute of Radiobiology and Agroecology.

Aray Ye. Temirzahnova, engineer, Institute of Radiation Safety and Ecology.

Gani M. Yesilkanov, engineer, Institute of Radiation Safety and Ecology.

Nurlan Zh. Mukhamediyarov, engineer, Institute of Radiation Safety and Ecology. 